\title{
Pagamento por serviços ecossistêmicos: as limitações e equívocos dos instrumentos econômicos de valoração da natureza
}

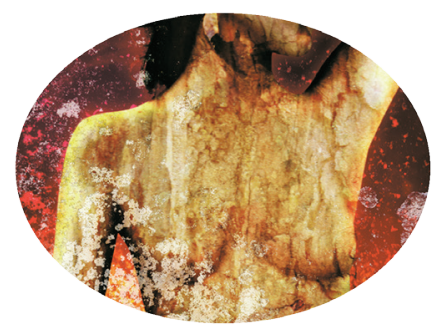

Glaubécia Teixeira da Silva* Elenise Faria Scherer**

\section{Resumo}

Os serviços ecossistêmicos são condições ou processos pelos quais os ecossistemas naturais e as espécies que neles vivem sustentam a vida humana e garantem a permanência dos demais elementos do ambiente. Cada ecossistema possui uma dinâmica de funcionamento distinta, atribuir uma escala de importância entre os vários níveis de serviços, leva à adoção de uma lógica capitalista em que alguns ecossistemas passam a ser considerados mais valiosos que outros. O Pagamento por Serviços Ambientais considera, em geral, o custo de recuperação de um serviço ambiental subestimando-se os custos de manutenção dos ecossistemas que os provém, o valor de existência e os custos sociais. Ao restringir-se ao valor de utilidade dos recursos ambientais ou dos serviços ecossistêmicos individualmente, os instrumentos de valoração não consideram a complexidade do sistema ambiental. Assim, os pagamentos por serviços ecossistêmicos enfrentam obstáculos econômicos, político-institucionais e informacionais que dificultam ou inviabilizam a sua implementação. Essas dificuldades ocorrem em função das falhas

\footnotetext{
* Doutoranda do Programa de Pós-Graduação em Ciências do Ambiente e Sustentabilidade na Amazônia PPG/Casa. Professora da Universidade do Estado do Amazonas. E-mail: glaubecia@hotmail.com

** Professora doutora do Programa de Pós-Graduação em Ciências do Ambiente e sustentabilidade na Amazônia - PPG/Casa. E-mail: elenise@internext.com.br
} 
tanto do mercado quanto da intervenção pública. Diante do exposto, cabe questionar se os instrumentos econômicos estabelecidos para valorar estes serviços ambientais são eficientes e eficazes no sentido de mensurar todo o custo do processo que envolve a manutenção dos serviços ecossistêmicos em sistemas complexos na Amazônia. O presente artigo fundamenta-se numa revisão de literatura relacionada aos temas serviços ecossistêmicos e o uso de instrumentos econômicos de valoração ambiental. Pretende-se analisar, à luz da epistemologia ambiental, como os instrumentos econômicos de pagamento por serviços ecossistêmicos podem configurar-se em mecanismos de controle e valoração/precificação da natureza e ressaltar a necessidade de desconstrução das relações que as populações tradicionais estabelecem entre si, bem como a forma que se apropriam dos recursos naturais, tendo como base os pressupostos teóricos que dão sustentação às discussões sobre a chamada economia verde e o entendimento da complexidade sistêmica do ambiente. Dessa forma, pretende-se discutir o grande desafio da atualidade: a adequação dos instrumentos econômicos, no sentido de englobar a totalidade dos serviços ecossistêmicos e as mudanças nas formas de intervenção pública nos modos de vida das populações tradicionais e das questões ambientais em âmbito global.

Palavras-chave: serviços ecossistêmicos; economia verde; valoração.

\begin{abstract}
Ecosystem services are the conditions and processes through which natural ecosystems and the species that inhabit them sustain human life and ensure the permanence of the other elements of the environment. Each ecosystem has distinct dynamic operation, assign a importance level among the levels of services, leads to the adoption of a capitalist logic that some ecosystems are now considered more valuable than others. Payment for Environmental Services considers, in general, the cost recovery of an ecosystem service underestimating the costs of maintaining ecosystem that derives the existence and value of social costs. When restricted to the utility value of environmental resources and ecosystem services individually, instruments valuation does not consider the environmental system complexity. Thus, payments for ecosystem services face economic, political-institutional and informational barriers that
\end{abstract}


prevent or impair their implementation. These difficulties occur because of failure of both market and government intervention. Given the above, one must question whether the economic instruments are established to value these environmental services are efficient and effective in measuring the cost of the process involves the maintenance of ecosystem services in complex systems in the Amazon. This paper is based on a literature review related to the topics ecosystem services and the use of economic instruments for environmental valuation. This paper is based on literature review issues related to ecosystem services and the use of economic instruments for environmental valuation. It is intended to analyze, in light of environmental epistemology, economic instruments such as payment for ecosystem services can configure up in control mechanisms and valuation/pricing and emphasize nature the need to deconstruct the relationships that traditional populations establish between themselves and the way they have ownership over natural resources, based on the theoretical assumptions that support the discussions on the so-called green economy understand the systemic complexity of the environment. Thus, we intend to discuss the great challenge of our time: the adequacy of economic instruments in the sense fully include ecosystem services and changes in the forms of government intervention in lifestyles traditional populations and environmental issues globally.

Keywords: ecosystem services; green economy; valuation.

\section{Introdução}

As mudanças no clima do planeta têm despertado, desde a década de 1970, grandes discussões sobre o uso dos recursos ambientais provenientes de fontes não renováveis e as consequências do aumento da produção e do consumo em nível global. A preocupação mundial com o desaparecimento desses recursos tem despertado a atenção de pesquisadores, investidores, gestores públicos e da sociedade em geral para a manutenção das fontes dos recursos ambientais ainda existentes. Dessa forma, a Amazônia se destaca nesse contexto por ser detentora de um enorme patrimônio natural representado pela grande biodiversidade e sociodiversidade presentes em seu vasto território.

No intuito de encontrar meios de manter os recursos ambientais e, 
consequentemente, os sistemas de suporte à vida no sistema ambiental, surge a necessidade de adoção de mecanismos que possam, ao mesmo tempo, manter as bases materiais de suporte à produção e à economia, bem como as bases de sustentação dos sistemas ambientais e seus complexos ecossistemas como um todo.

Considerando a necessidade de manutenção do sistema ambiental e, ainda, a necessidade de reverter a situação de crise ambiental subjacente a uma crise ética, a economia verde, por meio da criação dos instrumentos econômicos de valoração dos serviços ecossistêmicos, mostra-se como uma alternativa de dinamização da economia por meio da expansão dos setores de baixo impacto ambiental.

Contudo, os instrumentos de pagamento por serviços ecossistêmicos apresentam limitações relativas aos equívocos na sua concepção, iniciando com a imprecisão conceitual sobre a dimensão desses serviços, e as limitações na aplicabilidade desses instrumentos constituídas pelas falhas de mercado, de informação e político-institucionais.

\section{Contextualização da "crise ambiental” em escala global}

O aumento excessivo do consumo de bens e serviços ambientais, a ameaça à permanência dos ecossistemas, a profunda desigualdade social e os altos índices de pobreza no mundo têm configurado uma crise ambiental que ameaça a sustentabilidade do sistema planetário. Considerando-se que o planeta Terra não é um sistema linear e os recursos naturais são finitos, o consumo exacerbado extrapola a capacidade de resiliência do ambiente. Desse modo, todas as ações, sejam das pessoas, dos governos e das corporações, geram perturbações nas interações existentes no sistema global gerando uma crise ambiental de fundo social. Os modos de produção de bens e serviços dependem de uma base material e a exploração desenfreada promove inúmeras perturbações no funcionamento dos sistemas naturais globais. A redução na disponibilidade dos recursos, as alterações nas condições climáticas e a destruição dos habitats de espécies animais e vegetais são exemplos disso. Assim, essa racionalidade econômica hegemônica configura-se como a causa da crise socioambiental que se traduz em uma crise ética, pois seu enfrentamento depende de profundas mudanças comportamentais e dos 
modelos de desenvolvimento econômico vigentes.

A constatação da existência de uma crise ambiental suscitou o aumento das iniciativas de inserção das dimensões sociopolíticas e ambientais como forma de promover mudanças na racionalidade capitalista hegemônica. Dessa forma, emerge a necessidade de reflexão sobre os modos de intervenção humana nos sistemas ecológicos e sociais.

A discussão sobre os temas ambientais e a necessidade de mudanças estruturais nos modos de produção e consumo teve início com as convenções capitaneadas pela Organização das Nações Unidas por meio do Programa das Nações Unidas para o Meio Ambiente (PNUMA). A Conferência das Nações Unidas sobre o Ambiente Humano realizada em 1972, em Estocolmo, pôs a dimensão ambiental na agenda política internacional e discutiu pela primeira vez as dependências entre desenvolvimento e meio ambiente (SACHS, 2008: 48), incluindo as questões sociais, políticas e econômicas. Essa conferência marcou o início dos confrontos entre as perspectivas dos países desenvolvidos e em desenvolvimento (NETO, CAMPOS, SHIGUNOV, 2009: 59).

A Comissão Brundtland, em 1987, apresentou críticas ao modelo de desenvolvimento adotado pelos países desenvolvidos, considerando que esse não seria o modelo adequado aos países em desenvolvimento, sob pena de serem esgotados rapidamente os recursos naturais restantes (NETO, CAMPOS, SHIGUNOV, 2009: 60-61).

Várias outras iniciativas mundiais ocorreram ao longo da segunda metade do século 20, com destaque para a ECO 92 - Conferência da ONU sobre Meio Ambiente e Desenvolvimento Sustentável, realizada no Rio de Janeiro e que teve como foco os conflitos existentes entre a necessidade do desenvolvimento e de proteção ambiental. As discussões geradas a partir desse evento mundial deram origem aos princípios que passaram a nortear as políticas ambientais em busca da sustentabilidade entre as atividades humanas e a manutenção dos ecossistemas.

Sachs (2008: 85-87) esclarece que o termo sustentabilidade é por vezes utilizado para expressar a dimensão ambiental; no entanto, possui diversas dimensões, quais sejam: sustentabilidade social (é a própria finalidade do desenvolvimento); cultural (consequência da anterior); ambiental (vem em decorrência das demais); distribuição territorial equilibrada de assentamentos humanos e suas atividades; sustentabilidade econômica (não pode anteceder 
as demais dimensões); sustentabilidade política (conduz todo o processo); e a sustentabilidade do sistema internacional para manter a paz. Jatobá, Cidade e Vargas (2009: 80) complementam sugerindo que, para haver sustentabilidade, é preciso que se pense o desenvolvimento não somente em uma abordagem ecológica e econômica, mas também social, pondo a justiça social no cerne da questão ambiental.

A "crise ambiental" se estabeleceu a partir do aumento da demanda de produtos e serviços, promovida pela maior disponibilidade de recursos financeiros que tem estimulado cada vez mais o consumo em massa. A cultura do consumismo nacional e internacional disseminou um processo econômico gerador de uma alta entropia que ameaça a condição de sustentabilidade do sistema planetário de suporte à vida (STAHEL, 1995: 107). A ideologia do consumo dissemina a lógica da acumulação mesmo à custa da ineficiência social e ambiental (MARX, 1975 apud STAHEL, 1995), assim, a cultura do consumismo interfere nas relações sociais, subjuga a condição humana e impõe-se como forma de segregação social. Os processos de destruição ecológica mais devastadores e a degradação socioambiental geram altos custos sobre os sistemas naturais e sociais (LEFF, 2001).

Embora existam iniciativas de recuperação do ambiente e da produção limpa, estas são ainda insuficientes para promover mudanças significativas nos padrões de consumo impostos pela mídia e pelas grandes corporações, ou seja, atualmente as sociedades, sobretudo as dos países que mantêm grande parte de seus recursos ambientais em razoável estado de conservação, tendem a seguir os padrões de produção e consumo dos países desenvolvidos do hemisfério Norte ao invés de criar estratégias próprias de desenvolvimento.

Leff (2000) alerta para a necessidade de uma nova racionalidade produtiva orientada pelos princípios de equidade e sustentabilidade do processo de desenvolvimento. Dessa forma, a mudança do paradigma hegemônico para o paradigma sistêmico - aproveitamento racional e ecologicamente sustentável dos recursos ambientais em benefício das pessoas, só será possível a partir da elaboração de uma nova teoria de produção sustentável, assim como a concretização de decisões políticas e da participação democrática da sociedade. A nova racionalidade requer a construção e desconstrução do mundo em uma "contracorrente do projeto homogeneizante da modernidade" (LEFF, 2011). Atualmente as discussões sobre as questões ambientais têm considerado a 
economia verde como uma proposta mais sustentável na tentativa de conciliar o desenvolvimento e a manutenção dos sistemas de suporte à vida.

\section{A economia verde e o pagamento por serviços ecossistêmicos}

O tema economia verde foi adotado a partir da Assembleia Geral das Nações Unidas, em 2009, e tornou-se um dos temas da RIO+20. A definição de economia verde proposta pelo PNUMA é a de um sistema econômico dominado por investimento, produção, comercialização, distribuição e consumo, de maneira a respeitar os limites dos ecossistemas, mas, também, como um sistema que produz bens e serviços que melhoram o ambiente, ou seja, que tenham um impacto ambiental positivo. A economia verde é considerada como aquela que "resulta em melhoria do bem-estar humano e equidade social, ao mesmo tempo em que reduz significativamente os riscos ambientais e a escassez ecológica" (PNUMA, 2011: 2).

A Terra é um organismo vivo (LOVELOCK, 2006) que se constitui em sistema aberto no qual as diversas unidades que o integram estabelecem interações entre si, é considerada como sistema cuja base material é finita especialmente no que tange àquela que sustenta os serviços ecossistêmicos.

O relatório da União Europeia, publicado em 2008, considera os serviços ecossistêmicos como os benefícios que as pessoas obtêm dos ecossistemas, incluem alimento, água potável, lenha, regulação climática, proteção de desastres naturais, controle de erosão, matéria-prima para a fabricação de medicamentos e recreação (EUROPEAN COMMUNITIES, 2008: 12). Os serviços ecossistêmicos são condições ou processos pelos quais os ecossistemas naturais e as espécies que neles vivem sustentam a vida humana e garantem a permanência dos demais elementos do ambiente. Diante da importância desses serviços, a economia verde se põe como alternativa para dinamizar a economia por meio da expansão dos setores de baixo impacto ambiental (CECHIN, PACINI, 2012).

Os serviços ecossistêmicos podem ser divididos em (EUROPEAN COMMUNITIES, 2008):

Serviços de Regulação: capacidade dos ecossistemas naturais e seminaturais de regularem processos ecológicos essenciais de suporte de vida 
por ciclos biogeoquímicos e outros processos da biosfera. Exemplo: regulação do ciclo hidrológico, ciclagem de nutrientes, controle de erosão etc.

Serviços de Produção: nutrientes captados pelos autótrofos que são convertidos em energia, dióxido de carbono, água e nutrientes que são então utilizados pelos produtores secundários para criar uma variedade ainda maior de biomassa viva, tais como: a produção de alimentos, de água etc.

Serviços de Informação: fornecem uma função essencial de referência, contribuindo para a manutenção da saúde humana, proporcionando oportunidades para a reflexão, enriquecimento espiritual, o desenvolvimento cognitivo, recreação e experiências estéticas, a exemplo dos aspectos paisagístico, religioso, cultural, do sentido de lugar e sentimento de pertencimento.

Serviços de Habitat: ecossistemas que fornecem refúgio e habitat para a reprodução de espécies vegetais e animais, contribuindo para a conservação in situ da diversidade biológica e genética e dos processos evolutivos. A sua manutenção é essencial para garantir os outros serviços.

Atualmente, existem correntes teóricas que fazem distinção entre os conceitos de serviços ambientais e serviços ecossistêmicos. De acordo com o Substitutivo ao Projeto de Lei n. ${ }^{\circ}$ 792, de 2007, os serviços ecossistêmicos são benefícios relevantes para a sociedade gerados pelos ecossistemas, em termos de manutenção, recuperação ou melhoramento das condições ambientais, nas modalidades de provisão, suporte, regulação e serviços culturais. Já os serviços ambientais são definidos como iniciativas individuais ou coletivas que podem favorecer a manutenção, a recuperação ou o melhoramento dos serviços ecossistêmicos (KHOURY, 2010). No presente trabalho consideraremos os serviços ecossistêmicos como essenciais à formulação da política de gestão ambiental no Estado do Amazonas e contingenciadores dos instrumentos econômicos de compensação ambiental.

A constatação da existência de riscos de esgotamentos dos recursos e o comprometimento dos sistemas de suporte à vida tem levado as várias esferas da sociedade e os governos dos países desenvolvidos e em desenvolvimento a repensarem o paradigma capitalista hegemônico e suas consequências sobre os sistemas terrestres, incluindo as ameaças sobre a sobrevivência humana. Uma das alternativas sugestionadas a partir do Protocolo do Kyoto é a criação de políticas de gestão ambiental que consideram o conhecimento ecológico como pré-requisito para a aplicação dos critérios econômicos. Tais critérios devem 
fazer parte de uma política ambiental norteadora dos sistemas produtivos.

Para Motta (2006: 10), a política ambiental é uma ação governamental que intervém na esfera econômica para atingir objetivos que os agentes econômicos não conseguem obter atuando livremente. Por conseguinte, a aplicação da política ambiental requer a utilização de instrumentos econômicos que se constituem em instrumentos de controle podendo ser mais ou menos rígidos, com a finalidade de atribuir um valor econômico aos serviços ambientais. De acordo com Espinoza et. al. (apud WUNDER et. al., 2010: 50),

[...] os pagamentos por serviços ambientais constituem uma das medidas mais apropriadas que devem adotar e aplicar os países da América Latina e Caribe, em caráter prioritário, como forma de mitigar, controlar e reverter os acelerados processos de deterioração do meio ambiente [...].

Os pagamentos por serviços ecossistêmicos (PSE) são pagamentos por um serviço ou pelo uso da terra que viabilizam garantir tal serviço e são particularmente importantes quando não é possível comprar e reservar terra para conservação, ou onde não é possível estabelecer áreas protegidas. LandedMills e Porras (apud ABRAMOWAY, 2010: 104)

estudaram 287 casos em quase todo o mundo mostrando a existência de promissores mercados voltados à valorização dos serviços ecossistêmicos prestados pelas florestas: conservação da biodiversidade, sequestro de carbono, proteção das bacias hidrográficas (água, solo, prevenção de secas e enchentes, controle da salinização e manutenção dos ambientes aquáticos) e exploração das belezas naturais são os quatro principais segmentos em que mercados podem ser explorados e, ao mesmo tempo, contribuir de maneira decisiva tanto para a resiliência dos ecossistemas como na luta contra a pobreza.

Os PSEs são alternativas aos usos degradantes do solo e das florestas, capazes de promover a preservação dos ecossistemas e melhorar as condições de vida das populações, constituem-se, portanto, um mercado potencial que deve ser considerado pelas políticas nacionais, estaduais e municipais. 
Em termos econômicos, um novo princípio em meio ambiente tem sido discutido como alternativa para a manutenção dos serviços ambientais de diversos ecossistemas, o princípio do protetor-recebedor (os outros dois princípios são poluidor-pagador e usuário-pagador). Países como a Costa Rica, El Salvador e México mostram experiências bem-sucedidas com o PSE. $\mathrm{Na}$ lógica dos PSEs, quem ajuda a conservar os recursos naturais deve ser recompensado pela manutenção da biodiversidade, visto que está fazendo um bem a toda a coletividade.

\section{As limitações e equívocos dos instrumentos econômicos de valoração ambiental}

Os mecanismos de valoração ambiental são estabelecidos com base no mercado cujo pagamento por serviços ambientais (PSA) é feito em dinheiro ou por meio de incentivos fiscais e compensações bilaterais entre as partes envolvidas: a iniciativa privada, os governos, as organizações não governamentais e os usuários em geral dos recursos naturais. Um agricultor/ pecuarista pode receber um pagamento pelas áreas que ele deixa de desmatar ou quando adota alternativas de uso do solo que não interrompam o fornecimento dos serviços ecossistêmicos já existentes, como a prática da agrofloresta, por exemplo. Esse pagamento reflete a perda de renda que o proprietário da terra ganharia se a floresta dele fosse convertida em pastos ou plantações. Não descarta, porém, a possibilidade de os produtores intensificarem suas atividades produtivas em áreas mais críticas, mesmo conservando áreas onde os impactos ambientais seriam menores. Nesse caso, o PSA estaria subsidiando as atividades produtivas de proprietários de terras e não as atividades de conservação dos serviços ecossistêmicos.

Os critérios para valorar os serviços ambientais, utilizados atualmente, são estabelecidos nas perspectivas econômicas e sociais. Para que ocorram os ganhos econômicos e sociais há uma perda de serviços ambientais e isso tem um custo. Geralmente as sociedades têm de escolher entre usos alternativos do ambiente natural e sua exploração maximizada. Para fazer uma escolha racional entre as alternativas de uso do ambiente é necessário saber quais são os serviços ambientais fornecidos pelos ecossistemas e, a partir daí, estabelecer um valor para esses serviços. 
Ocorre que, geralmente, prevalece a alternativa de uso com maior rentabilidade econômica (é a relação custo versus benefício econômico). Como, em geral, os responsáveis pela extração dos recursos naturais não recebem nenhum incentivo para manter os serviços ecossistêmicos, tornase mais vantajoso para eles a extração e comercialização indiscriminada dos recursos. A racionalidade capitalista, na maioria das vezes, vence a batalha contra a racionalidade ambiental. Leff (2001: 129) afirma que "no conceito de racionalidade ambiental subjaz um conceito de 'adaptação' que predomina sobre o conceito de 'domínio' da natureza, no qual se apoia a racionalidade capitalista e os paradigmas da ciência moderna”, para se promover uma racionalidade ambiental é necessário remontar toda a estrutura do modo de produção capitalista de forma particular em cada nação, Estado, economia e em cada povo.

A mensuração da totalidade dos serviços ecossistêmicos é o grande desafio da atualidade, pois cada ecossistema possui uma dinâmica de funcionamento distinta. Atribuir uma escala de importância e valor monetário aos vários níveis de serviços leva à adoção de uma lógica capitalista em que alguns ecossistemas passam a ser considerados mais valiosos que outros porque provêm maiores benefícios econômicos ou porque os riscos que envolvem as perdas em níveis local, regional e global são mais altos, o que acaba comprometendo a sua análise sistêmica e, consequentemente, a sustentabilidade do processo. Diante das incertezas sobre a complexidade dos ecossistemas, acredita-se que o PSE deva ser definido mais livremente, de modo a poder agregar novos conhecimentos e informações para maximizar os benefícios sociais.

Para Candotti (2010: 29),

a questão dos serviços ambientais é mais ampla e não pode ser recortada e resolvida apenas em termos de oferta, demanda, preços e mercado, uma vez que em sua grande parte estes serviços ainda devem ser qualificados e requerem para serem explorados investimentos que ainda não foram dimensionados, não sendo portanto o mercado (que os desconhece) bom conselheiro.

No PSA considera-se, em geral, o custo de recuperação de um serviço ambiental subestimando-se os custos de manutenção e o valor de existência 
dos recursos ambientais e os serviços ecossistêmicos. Assim, a complexidade do sistema ambiental não é considerada na formação dos instrumentos de valoração:

E a armadilha em se comparar tudo na métrica monetária está na falsa impressão de substitutibilidade. Embora o dinheiro seja intercambiável, tanto bens e serviços reais produzidos quanto recursos naturais e serviços ecossistêmicos não o são com a mesma facilidade (CECHIN, PACINI, 2012: 128).

De acordo com Motta (2006), o valor econômico dos recursos ambientais (Vera) deriva dos seus atributos, podendo esses estarem associados ao seu valor de uso (VU) e valor de não uso (VNU). O valor de uso divide-se em valor de uso direto (VUD) - aquele que os indivíduos atribuem a um recurso ambiental por utilizarem-se diretamente deste, por exemplo, a provisão de alimento, valor de uso indireto (VUI) - atribuído a um recurso quando o benefício do uso deriva de funções ecossistêmicas - por exemplo, o controle de erosão, proteção de mananciais. O valor de opção (VO) quando se atribui um valor à preservação de um recurso ameaçado para uso direto ou indireto no futuro - por exemplo, as propriedades genéticas de plantas em florestas tropicais. O valor de não uso ou valor de existência (VE) está dissociado do uso e deriva de questões morais, éticas, culturais, altruístas etc. representa o desejo do indivíduo em manter certos recursos para gerações futuras mesmo que ele próprio nunca venha a utilizá-lo.

Os fundamentos metodológicos de valoração econômica do ambiente (MOTTA, 2005: 14) são classificados em: 1. métodos da função de produção que inclui os métodos de produtividade marginal e de mercados de bens substitutos; 2. métodos em função da demanda constituído pelos métodos de mercado de bens complementares (preços hedônicos e do custo de viagem) e métodos de valoração contingente e os custos de substituição dos serviços ecológicos.

As metodologias têm sido desenvolvidas sob a abordagem utilitarista, o valor do uso ou da disposição a pagar dos indivíduos pelos serviços ambientais que desejam manter.

Leff (2009: 180) afirma que os instrumentos de valoração ambiental 
atualmente utilizados apresentam limitações por conta das dificuldades de se traduzirem valores culturais, objetivos culturais e tempos ecológicos num sistema de preços de mercado, a impossibilidade de descontar um futuro incerto. $\mathrm{O}$ autor destaca que esses instrumentos econômicos têm dificuldades para atualizar os custos e benefícios futuros de uma estratégia produtiva e os processos ecológicos de longo prazo; portanto, não conseguem precificar uma série de processos que escapam às tentativas metodológicas de mensuração da natureza.

As fórmulas de cálculo econômico estão atreladas ao modelo de produção e consumo com características atuais que consideram apenas as condições de oferta de recursos e necessidades atuais, portanto os objetivos qualitativos, assim como as potencialidades, riscos e incertezas que implicam uma mudança global e o desenvolvimento sustentável, não são facilmente integrados como valores de mercado aos instrumentos de cálculo econômico, de acordo com Stahel (1995: 108), "a sustentabilidade material do processo econômico repousa no limite qualitativo”.

Atualmente, os créditos de carbono constituem-se em mercado de PSA mais difundido no mundo. Sua implementação foi estimulada a partir do Protocolo de Kyoto como forma de mitigação dos efeitos do aquecimento global. Os instrumentos utilizados para valoração ambiental são diversificados, no Brasil e no mundo, existem variados projetos e políticas públicas de conservação embasados pelo PSA, tais como: ICMS ecológico, compensação ambiental, reposição florestal, isenção fiscal para Unidades de Conservação e programas de estímulo aos pequenos agricultores e pecuaristas que incorporam práticas menos impactantes em sua produção etc. O governo federal mexicano, por exemplo, premia financeiramente comunidades e donos de propriedades rurais que preservam suas florestas e áreas de mananciais; o governo da Costa Rica criou uma taxa que incide sobre o consumo de água e gasolina do país, cuja arrecadação é revertida aos proprietários de florestas.

Nos sistemas complexos como a Amazônia, o desafio de valorar os serviços ambientais de modo a agregar os serviços ecossistêmicos exige esforço ainda maior. A biodiversidade da Amazônia, que ocupa um lugar especial no imaginário do brasileiro e também de muitos estrangeiros, é vista como um recurso estratégico que pode contribuir decisivamente para o desenvolvimento nacional (CLEMENT, FONSECA apud GEEA, 2008); contudo, não há 
uma definição clara dos mecanismos que o viabilizem, pois quais seriam os indicadores capazes de mensurar o valor de uma paisagem ou de uma experiência vivida em dado espaço? Considerando-se todos os componentes da biodiversidade e sociodiversidade, acredita-se que os mecanismos utilizados para pagamentos dos serviços ambientais no Amazonas ainda estão longe de medir o valor de tudo isso, sobretudo, pelo caráter da heterogeneidade dos distintos ecossistemas presentes na Amazônia.

O Estado do Amazonas iniciou, em 2010, a elaboração da Política Estadual de Serviços Ambientais, esta iniciativa surgiu a partir do Fórum Amazonense de Mudanças Climáticas (Famc) que indicou como ação prioritária o desenvolvimento do marco legal que assegurasse os serviços ambientais providos pela floresta, assim como o reconhecimento das populações diretamente envolvidas com a sua manutenção.

Dentre as estratégias políticas estaduais encontra-se o Programa Bolsa Floresta (PBF) que foi instituído em 2007 pelo Governo do Estado do Amazonas por meio da Secretaria Desenvolvimento Sustentável (SDS). A institucionalização do programa se deu por intermédio da Lei n. ${ }^{\circ}$ 3.135, sobre Mudanças Climáticas, Conservação Ambiental e Desenvolvimento Sustentável do Amazonas, e da Lei Complementar n. ${ }^{\circ}$ 53, sobre o Sistema Estadual de Unidades de Conservação (Seuc) para valorizar e compensar economicamente os esforços de conservação ambiental das famílias moradoras de unidades de conservação do Estado do Amazonas. O PBF está sendo implementado nas unidades de conservação: RDS Cujubim, Mamirauá, Rio Negro, PiagunçuPurus, Uatumã, Uacari, Amanã, Madeira, Carumã, Juma, Amapá, Florest Maués, Resex Catuá-Ipixuna e Rio Gregório, APA Rio Negro, e apresenta quatro modalidades (FAS, 2008):

Bolsa Floresta Família - consiste em um pagamento mensal de $\mathrm{R} \$ 50,00$ para as famílias moradoras e usuárias das Unidades de Conservação estaduais em contrapartida essas famílias se comprometem a reduzir o desmatamento e valorizar a floresta em pé;

Bolsa Floresta Associação - é destinada às associações dos moradores das UCs do Estado com o objetivo de fortalecer a organização e o controle social do programa;

Bolsa Floresta Renda - este componente é destinado ao apoio à produção sustentável: peixe, óleos vegetais, frutas, mel etc. equivale a $\mathrm{R} \$ 350,00$ pagos 
ao ano por família. A meta é promover arranjos produtivos e certificação de produtos que aumentem o valor recebido pelo produtor; e

Bolsa Floresta Social - este componente é destinado à melhoria da educação, saúde, comunicação e transporte, componentes básicos para a construção da cidadania dos guardiões da floresta com o apoio do poder público e iniciativa privada.

O PBF é aplicado em 15 UCs e coordenado pela Fundação Amazonas Sustentável (FAS), instituição vinculada à SDS, contando com a parceria de empresas de grande porte, tais como a Coca-Cola, a Yamamay, a Rede Marriot de Hotéis e a Tuv-Sud, que atuam na RDS do Juma com o programa local de desenvolvimento sustentável e geração de créditos de carbono por desmatamento evitado (FAS, 2008) e seus cofundadores e mantenedores o banco Bradesco e o Governo do Estado do Amazonas que, juntamente com os parceiros, geraram um aporte de U\$ 60 milhões para remunerar as famílias do PBF somente em 2008.

É visível que, além das iniciativas governamentais, a sociedade civil e organizações privadas investem em projetos de PSA. Essas iniciativas não abrangem completamente os serviços ecossistêmicos porque suas dinâmicas complexas os tornam difíceis de mensurar. A maioria dos PSAs remunera as famílias e pequenos produtores pela preservação de áreas naturais, mediante a adoção de práticas produtivas mais sustentáveis como os sistemas agroflorestais e redução do desmatamento pelo uso de atividades econômicas alternativas. O REDD (Redução de Emissões por Desmatamento e Degradação), que mais recentemente foi denominado de REDD+, é um exemplo de instrumento econômico de compensação adotado por países cujos estoques de recursos ambientais ainda se mantêm. De acordo com o PNUMA, o REDD+

agrega a conservação, gestão sustentável de florestas e a valorização das reservas de carbono da floresta à lista das atividades elegíveis, representa um plano de PSE de múltiplas camadas com transferências de financiamento entre os países industrializados e os países em desenvolvimento na troca pelas reduções de emissões, e novas transferências do plano nacional de proprietários rurais e comunidades florestais (PNUMA, 2011: 32). 
É inegável que o REDD+ é um importante instrumento econômico, mas não deverá ser o único, tomado como medida compensatória pelas emissões dos países mais desenvolvidos. O PNUMA considera que o REDD+ pode ser a melhor oportunidade atual de facilitar a transição para uma economia verde, entretanto não deverá ser o único meio para resolver problemas de ordem estrutural, político-institucional e econômica. Apesar de não estarem claramente definidos na política ambiental do Estado do Amazonas, os instrumentos de compensação apresentados anteriormente poderiam compor mecanismo de PSE, mas frequentemente são classificados como PSA.

Definir um método de valoração dos serviços ecossistêmicos é tarefa complexa porque envolve decisões contingenciadas por forças endógenas, que podem ser exemplificadas pelas ações de pequenos agricultores, e exógenas a exemplo das ações de grandes corporações que influenciam o mercado de commodites, nas escalas temporal, espacial e organizacional. A escala temporal refere-se aos efeitos que as mudanças no ecossistema promovem ao longo prazo e pouco evidentes no curto prazo. A escala espacial considera as mudanças ambientais em nível local que refletem em níveis mais amplos atingindo ecossistemas diversos. Considerando as dimensões territoriais e os complexos ecossistemas da Amazônia, os instrumentos de valoração dos serviços ecossistêmicos tornam-se reducionistas porque adotam os modelos que reconhecidamente apresentam limitações.

As limitações dos instrumentos econômicos são resultantes de falhas de mercado, de intervenção pública e da assimetria de informação (HERRERO, 2001; EUROPEAN COMMUNITIES, 2008), em que o mercado é classificado como um processo político que determina a situação final. Segundo Farley e Constanza (2010), ao considerarem os mercados como sistemas de troca voluntária em que os preços são determinados pela interação da oferta e da demanda, então a maioria dos serviços do ecossistema tem características físicas que os tornam mal adaptados para o mercado.

Pode-se dizer que existe falha de mercado quando a situação real não corresponde à solução ideal, seria a condição em que oferta e demanda se igualam. Considerando a questão ambiental a falha de mercado consiste nas externalidades. Os tipos mais comuns de falhas de mercado residem na falta de concorrência perfeita, falha de informação - para serviços como o da beleza cênica é difícil mensurar a oferta e a demanda, ausência de "mercados" para a 
conservação de espécies e para a maioria dos serviços de regulação e suporte dos ecossistemas.

\section{Para finalizar}

Os mecanismos podem ser diversos, mas os objetivos são os mesmos: valorar os serviços ecossistêmicos que são fornecidos pelos ecossistemas naturais. Existem vantagens e desvantagens, riscos e oportunidades na adoção dos mecanismos descritos anteriormente. É certo, porém, que os instrumentos econômicos de pagamento por serviços ecossistêmicos sozinhos não se configuram nos únicos meios de resolver os problemas advindos da crise ambiental instalada, sobretudo, pelo fato de que a real crise está relacionada às questões éticas. Há de se considerar a defesa da ética como elemento essencial para a valoração dos serviços ambientais e na elaboração de políticas públicas que norteiem as decisões dos governos no sentido de garantir a sustentabilidade do uso dos recursos ambientais sem comprometer de forma irreversível o fornecimento dos serviços ecossistêmicos necessários para a manutenção da vida no planeta. Para isso, os países ricos e pobres devem assumir novas responsabilidades diante desse desafio que é manter a vida na Terra, com uma postura mais ética.

É um tanto utópico pensar que a racionalidade capitalista se converterá rapidamente em uma racionalidade ambiental, visto que durante muito tempo se imaginou que os recursos naturais eram inesgotáveis. O processo de perda da biodiversidade nos diversos ecossistemas existentes no planeta perpassa pelo aumento do consumo de bens e serviços que cresce num ritmo muito superior ao tempo de resiliência da natureza. A ação antrópica de explorar o máximo de recursos ao menor custo tem diminuído no curto e no longo prazos a capacidade de regeneração da natureza e afetado as interações ecossistêmicas. Nesse ritmo, muitos serviços ambientais são perdidos e, dificilmente, poderão ser substituídos por meios tecnológicos, o que compromete a sustentabilidade desses ecossistemas.

O paradigma econômico dominante não reconhece satisfatoriamente as contribuições que os ecossistemas proporcionam o que, inevitavelmente, gera a necessidade de se criar um novo paradigma mais abrangente. As decisões econômicas desconsideram as falhas do mercado e da regulação, além disso, 
as políticas públicas não promovem níveis adequados de conservação da biodiversidade e dos ecossistemas, e tendem a constituir uma base insustentável do crescimento da sociedade especialmente daquelas cujos valores de cidadania são pouco ou quase nunca estimulados.

O pagamento por serviços ambientais torna-se mais vantajoso na medida em que a preservação dos recursos ambientais seja mais lucrativa para o prestador desses serviços, contrapondo-se à destruição total dos recursos. Contudo, seriam necessários esforços teórico-metodológicos no sentido de realizar estudos interdisciplinares com o objetivo de alcançar as dimensões socioambientais e econômicas sob a ótica de uma abordagem sistêmica. Além disso, faz-se mister a criação de políticas ambientais eficazes do ponto de vista da redução: do consumo de energia de fontes poluentes, de recursos ambientais e da demanda por maiores espaços como é o caso da agricultura extensiva.

A economia verde poderia ser uma saída desde que se consiga manter baixos níveis de impactos ambientais e que os países mais pobres não sejam obrigados a assumirem a responsabilidade de conservação ambiental sozinhos, enquanto os países ricos mantêm os mesmos modelos de crescimento econômico. Somam-se às correções das falhas de mercado e as falhas da intervenção pública que na maioria das vezes estão relacionadas à ignorância sobre a complexidade dos sistemas ambientais e a prevalência dos interesses privados. Os PSEs podem ser mais eficazes se as metodologias utilizadas empregadas forem capazes de medir os grandes benefícios que os ecossistemas e a biodiversidade proporcionam ao bem-estar humano.

\section{Referências}

ABRAMOWAY, Ricardo. Desenvolvimento sustentável: qual a estratégia para o Brasil. Novos Estudos, 87, 2010.

CANDOTTI, Ennio. Notas sobre os serviços meio-ambientais. In: AMAZONAS. Governo do Estado. O valor dos serviços da natureza: subsídios para políticas públicas de serviços ambientais no Amazonas / Secretaria de Estado de Meio Ambiente e Desenvolvimento Sustentável. Manaus: SDS / Ceclima, 2010.

CECHIN, Andrei; PACINI, Henrique. Economia verde: por que o otimismo 
deve ser aliado ao ceticismo da razão. Estudos Avançados, 26 (74), 2012.

EUROPEAN COMMUNITIES. A economia dos ecossistemas e da biodiversidade: um relatório preliminar. Reino Unido: Cambridge, 2008.

FARLEY, Joshua; COSTANZA, Robert. Payments for ecosystem services: from local to global. Ecological Economics, 69 (2010)2.060-2.068. Disponível em: $<$ http:// www.elsevier.com/locate/ecolecon>. Acesso em: maio de 2012.

FAZ - FUNDAÇÃO AMAZONAS SUSTENTÁVEL. Relatório de gestão 2008. Disponível em: < http://www.fas-amazonas.org/pt/useruploads/files/ relatorio_gestao_2008.pdf> Acesso em outubro de 2011.

GEEA, Grupo de Estudos Estratégicos Amazônicos. Mudanças climáticas, água no mundo moderno, biodiversidade amazônica. VAL, Adalberto Luís; SANTOS, Geraldo Mendes dos (Orgs.). Manaus: Inpa, 2008.

HERRERO, Luis M. Jiménez. Desarrollo sostenible y economía ecológica: integración médio ambiente-desarrollo y economia-ecología. Madrid: Editorial Síntesis S/A, 2007.

JATOBÁ, Sérgio Ulisses; CIDADE, Lúcia Cony; VARGAS, Glória Maria. Ecologismos, ambientalismo e ecologia política. Sociedade e Estado, Brasília, v. 24, n. ${ }^{\circ}$ 1, p. 47-87, jan./abr., 2009.

KHOURY. Substitutivo ao Projeto de Lei n. ${ }^{\circ}$ 792, de 2007. Disponível em: <http:// www.camara.gov.br/sileg/integras/825489.pdf>

LEFF, Enrique. Saber ambiental: sustentabilidade, racionalidade, complexidade, poder. Tradução: Lúcia Mathilde Endlich Orth. 8. ${ }^{a}$ ed. Petrópolis, RJ: Vozes, 2011.

LOVELOCK, James. Gaia: cura para um planeta doente. Trad: Aleph Teruya Eichemberg e Newton Roberval Eichemberg. São Paulo: Cultrix, 2006.

MOTA, José Aroudo. O valor da natureza: economia e política dos recursos ambientais. Rio de Janeiro: Garamond, 2001.

NETO, Alexandre Shigunov; CAMPOS, Lucila M. de Souza; SHIGUNOV, Tatiana. Fundamentos da Gestão Ambiental. Rio de Janeiro: Editora Ciência Moderna Ltda., 2009.

PNUMA - Programa das Nações Unidas para o Meio Ambiente. Caminhos 
para o desenvolvimento sustentável e a erradicação da pobreza - síntese para tomadores de decisão, 2011.

SACHS, Ignacy. Desenvolvimento: includente, sustentável, sustentado. Rio de Janeiro: Garamond, 2008.

WUNDER, Sven; BÖRNER, Jan; TITO, Marcos Rügnitz; PEREIRA, Lígia. Pagamentos por serviços ambientais: perspectivas para a Amazônia Legal. Brasília: MMA, 2008. 